\title{
Optimal Heater Control with Technology of Fault Tolerance for Compensating Thermoforming Preheating System
}

\author{
Zhen-Zhe Li, Tai-Hong Cheng, Yun-De Shen, and Dong-Ji Xuan \\ College of Mechanical and Electrical Engineering, Wenzhou University, Higher Education Park, Wenzhou, Zhejiang 325035, China \\ Correspondence should be addressed to Dong-Ji Xuan; xuandongji@163.com
}

Received 21 July 2014; Revised 4 October 2014; Accepted 17 October 2014

Academic Editor: Xing Chen

Copyright (c) 2015 Zhen-Zhe Li et al. This is an open access article distributed under the Creative Commons Attribution License, which permits unrestricted use, distribution, and reproduction in any medium, provided the original work is properly cited.

\begin{abstract}
The adjustment of heater power is very important because the distribution of thickness strongly depends on the distribution of sheet temperature. In this paper, the steady state optimum distribution of heater power is searched by numerical optimization in order to get uniform sheet temperature. In the following step, optimal heater power distribution with a damaged heater was found out using the technology of fault tolerance, which will be used to reduce the repairing time when some heaters are damaged. The merit of this work is that the design variable was the power of each heater which can be directly used in the preheating process of thermoforming.
\end{abstract}

\section{Introduction}

Currently, the properties of the composite materials have been improved with development of the materials science and engineering. The study on the composite materials in the past was mainly focused on the chemical components and the physical structures. There is a trend that the composite materials take the place of the original metal materials in some engineering fields with development of the properties of the composite materials. Therefore, the study on the forming performance of the composite materials is also important.

Thermoforming is one of the most versatile and economical processes available for shaping polymer products, but obtaining a uniform thickness of final products using this method is difficult. Thermal management of thermoforming processes is very important because the thickness distribution strongly depends on the distribution of the sheet temperature $[1,2]$.

In order to improve the performance of final products and decrease the manufacturing cost, the design variables of thermoforming system and the operating parameters should be optimized. For realizing the optimization, the processes of thermoforming should be simulated. But, the simulation models for these processes of thermoforming have not been systematically constructed well. Therefore, the engineers only depend on trial and error. The design efficiency is too low, and design and manufacturing cost cannot be decreased significantly when using the method based on trial and error.

For simulating the preheating process of thermoforming, the complex phenomena such as phase change should be considered. Many researchers have studied the preheating process of thermoforming using many kinds of techniques. The materials used for thermoforming have their own absorption bands, and the ceramic heaters can be considered in which only the surfaces of the sheet are heated by the heaters. Therefore, the temperature between the surface and the center of the sheet is significantly different. In order to solve this problem, Jeffery and so forth have applied the infrared heaters to the preheating system of thermoforming, but the problem has not been solved ultimately due to the properties of the materials used for thermoforming [3-8].

The optimization study should be carried out for satisfying the requirements about the size, the operating conditions, and so forth defined by the users. Many researchers have studied the optimization of thermoforming processes using a lot of techniques such as numerical optimization, neural network, and design of experiments [9-14].

The focus of this study has been set to the preheating process of thermoforming. When the temperature of ABS (Acrylonitrile-Butadiene-Styrene) sheet is heated to over 


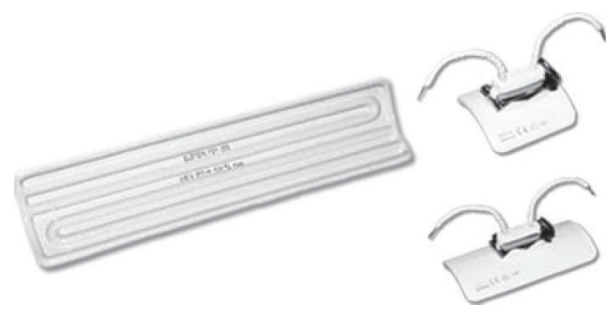

FIGURE 1: Ceramic heater.

glass transition temperature in the preheating process, the specific heat of ABS sheet is significantly changed, and the heat caused by radiation heat transfer and convection heat transfer is also changed. So, nonlinear problem should be considered because of variation of properties and operating condition. At first, the steady state optimum distribution of heater power is searched by a numerical optimization in order to get uniform sheet temperature. If the final temperature of sheet is considered, unsteady analysis must be required. To reduce the analysis time, mean value of initial and objective temperature is used in the calculation of steady state. In the following step, the optimal heater power distribution under the condition of having a damaged heater was found out using the technology of fault tolerance, which will be used to reduce the repairing time when some heaters are damaged.

\section{Analysis Model and Governing Equation}

2.1. Analysis Model. In this study, the ceramic heater shown in Figure 1 was considered. The feature of the ceramic heaters in the preheating chamber was shown in Figure 2. In the preheating process, ABS sheet was located as shown in Figure 3. The size of the sheet is $2 \mathrm{~m} \times 1 \mathrm{~m} \times 0.003 \mathrm{~m}$. There are $80(10 \times$ 8 ) heaters in the upper and lower sides, respectively, and the heating time is $100 \mathrm{~s}$. The distance between the heaters and the sheet is $0.2 \mathrm{~m}$. The temperature in the forming machine is set as $303 \mathrm{~K}$. The convection between the heater and outside was neglected. There is power input $\left(q_{\text {elec }}\right)$ in each heater during the heating time. The maximum available heating power of each heater is $650 \mathrm{~W}$.

The sheet and the heater were assumed as diffuse, gray surface, and the environment was assumed as blackbody. The emissivities of the sheet and the heater are 0.85 and 0.9 , respectively.

\subsection{Governing Equation}

2.2.1. Radiation Heat Transfer. Net Radiation Method was used to calculate radiation heat transfer. The following equation can be obtained using heat from the heater and the surface temperature of sheet [15]:

$$
\begin{gathered}
\sum_{j=1}^{N} a_{k j} J_{j}=C_{k} \\
a_{k j}=\left\{\begin{array}{l}
\delta_{k j}-F_{k-j} \\
\delta_{k j}-\left(1-\varepsilon_{k}\right) F_{k-j},
\end{array}\right.
\end{gathered}
$$

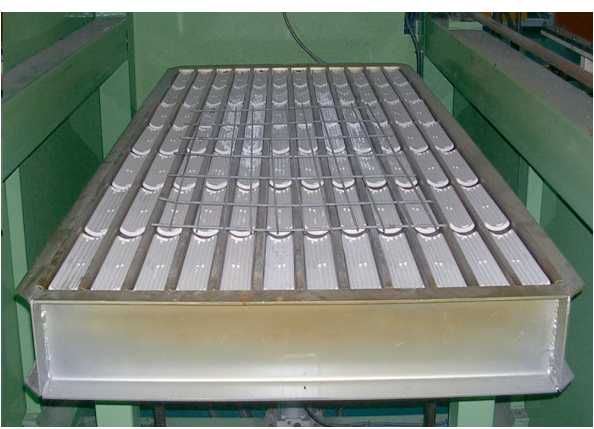

FIGURE 2: Feature of installed heaters in heating chamber.

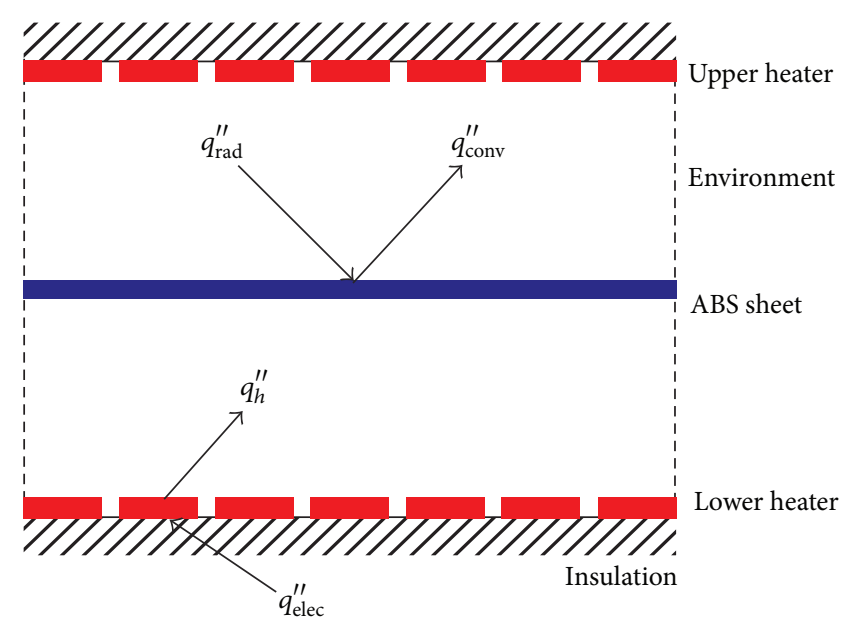

FIGURE 3: Schematic of model.

where

$$
\begin{gathered}
C_{k}=\left\{\begin{array}{cc}
\frac{q_{h, k}}{A_{k}}-\sigma T_{\infty}^{4} & 1 \leq k \leq n_{h} \\
\varepsilon_{k} \sigma T_{k}^{4}-\sigma T_{\infty}^{4} & n_{h}+1 \leq k \leq n_{k}+n_{s}
\end{array}\right. \\
\delta_{k j}= \begin{cases}1 & \text { when } k=j \\
0 & \text { when } k \neq j,\end{cases}
\end{gathered}
$$

where $J_{j}$ is the radiosity of $j$ th element $\left(\mathrm{Wm}^{-2}\right) ; F_{k-j}$ is the view factor from $k$ surface to $j$ surface; $\varepsilon_{k}$ is the emissivity of $k$ th element; $A_{k}$ is the area of $k$ th element $\left(\mathrm{m}^{2}\right) ; \sigma$ is the Stefan-Boltzmann constant $\left(5.67 \times 10-8 \mathrm{Wm}^{-2} \mathrm{~K}^{-1}\right)$; and $T_{\infty}$ is the environmental temperature $(\mathrm{K})$.

Using (4), the heat flux can be obtained using the calculated radiosity, and the temperature of the heater can be calculated by using (5). Consider

$$
\begin{gathered}
q_{\mathrm{rad}, j}^{\prime \prime}=-\frac{\varepsilon_{j}}{1-\varepsilon_{j}}\left(\sigma T_{j}^{4}-J_{j}\right) \quad j=n_{h}+1 \sim N \\
T_{j}=\sqrt[4]{\frac{\left(\left(\varepsilon_{j} /\left(1-\varepsilon_{j}\right)\right) q_{j}^{\prime \prime}+J_{j}\right)}{\sigma}} \quad j=1 \sim n_{h} .
\end{gathered}
$$


2.2.2. Convective Heat Transfer. Natural convection must be considered to analyze the preheating process of thermoforming [16]. The heat transfer coefficient $(h)$ can be calculated using Goldstei, Lloyd, and Moran's correlation. Equations (6) and (7) can be used to calculate the heat transfer coefficient of the upper surface of the sheet, and (8) can be used to obtain the heat transfer coefficient of the lower surface of the sheet [16], where $k$ is the thermal conductivity $\left(\mathrm{Wm}^{-1} \mathrm{~K}^{-1}\right)$. Consider

$$
\begin{aligned}
& \frac{\bar{h} L}{k}=0.54 \mathrm{Ra}_{L}^{1 / 4} \quad\left(10^{4} \leq \mathrm{Ra}_{L} \leq 10^{7}\right) \\
& \frac{\bar{h} L}{k}=0.15 \operatorname{Ra}_{L}^{1 / 3} \quad\left(10^{7} \leq \mathrm{Ra}_{L} \leq 10^{11}\right) \\
& \frac{\bar{h} L}{k}=0.27 \operatorname{Ra}_{L}^{1 / 4} \quad\left(10^{5} \leq \mathrm{Ra}_{L} \leq 10^{10}\right) .
\end{aligned}
$$

The characteristic length $(L)$ is formulated as (9), and Rayleigh number $\left(\mathrm{Ra}_{L}\right)$ is expressed as (10). Consider

$$
\begin{gathered}
L \equiv \frac{A_{s}}{P} \\
\operatorname{Ra}_{L}=\left(\frac{g \beta\left(T-T_{\infty}\right) L^{3}}{v a}\right),
\end{gathered}
$$

where $P$ is the length of the circumference $(\mathrm{m}) ; g$ is the acceleration of gravity $\left(\mathrm{m} / \mathrm{s}^{2}\right) ; \beta$ is the volume expansion coefficient of air $\left(\mathrm{K}^{-1}\right) ; v$ is the dynamic viscosity of air $\left(\mathrm{m}^{2} \mathrm{~s}^{-1}\right)$; and $a$ is the thermal diffusivity of air $\left(\mathrm{m}^{2} \mathrm{~s}^{-1}\right)$.

The convective heat transfer from the sheet to the environment $\left(q_{\text {conv }, j}^{\prime \prime}\right)$ is obtained by using the calculated heat transfer coefficient.

2.2.3. Conductive Heat Transfer. The conductive heat transfer is used to simulate the sheet's preheating process, and it was simplified to a $1 \mathrm{D}$ problem through the direction of the sheet's thickness [17]. Fully implicit method is used as (11), and the boundary condition is expressed as (12) [18-20], where $\rho$ is the density of ABS sheet $\left(\mathrm{kg} / \mathrm{m}^{-3}\right)$. Consider

$$
\begin{gathered}
\frac{T_{i}-T_{i}^{\mathrm{old}}}{\Delta t}=\frac{k}{\rho c} \frac{T_{i+1}-2 T_{i}+T_{i-1}}{\Delta z^{2}} \\
q_{\mathrm{in}, j}^{\prime \prime}=q_{\mathrm{rad}, j}^{\prime \prime}-q_{\infty \mathrm{on}, j}^{\prime \prime} \quad j=n_{h}+1 \sim N .
\end{gathered}
$$

\section{Optimal Heater Power Distribution}

The distribution of the heater power inputs in each position is important to obtain uniform temperature distribution of ABS sheet. Using (13), the requirement of heat flux heated from initial temperature $\left(T_{i}\right)$ to objective temperature $\left(T_{f}\right)$ can be calculated. The temperature-dependent specific heat of ABS sheet was from our previous research [21]. Consider

$$
q_{\text {req, } j}^{\prime \prime}=\frac{m_{j}}{2 t_{h} A_{j}} \int_{T_{i}}^{T_{f}} C_{p}(T) d T,
$$

TABLE 1: Optimal power distribution of heaters on upper side.

\begin{tabular}{ccccccccc}
\hline$\%$ & 1 & 2 & 3 & 4 & 5 & 6 & 7 & 8 \\
\hline 1 & 100.0 & 80.7 & 88.5 & 86.4 & 86.3 & 88.6 & 80.7 & 100.0 \\
2 & 49.8 & 0.0 & 0.0 & 0.0 & 0.0 & 0.0 & 0.0 & 49.8 \\
3 & 8.7 & 11.5 & 28.0 & 22.9 & 23.0 & 27.8 & 11.6 & 8.6 \\
4 & 70.8 & 34.5 & 29.8 & 31.2 & 30.8 & 30.1 & 34.3 & 70.9 \\
5 & 30.7 & 12.7 & 22.3 & 19.1 & 19.6 & 21.9 & 13.0 & 30.5 \\
6 & 30.5 & 13.0 & 21.9 & 19.6 & 19.1 & 22.4 & 12.7 & 30.6 \\
7 & 70.9 & 34.3 & 30.1 & 30.8 & 31.2 & 29.8 & 34.5 & 70.8 \\
8 & 8.6 & 11.6 & 27.8 & 23.0 & 22.9 & 28.0 & 11.5 & 8.6 \\
9 & 49.8 & 0.0 & 0.0 & 0.0 & 0.0 & 0.0 & 0.0 & 49.8 \\
10 & 100.0 & 80.6 & 88.6 & 86.3 & 86.4 & 88.5 & 80.7 & 100.0 \\
\hline
\end{tabular}

where $t_{h}$ is the heating time $(s) ; m_{j}$ is the mass of $j$ th element $(\mathrm{kg})$; and $C_{p}(T)$ is the temperature-dependent specific heat of ABS sheet $\left(\mathrm{Jkg}^{-1} \mathrm{~K}^{-1}\right)$.

To find out the optimal distribution of heater power inputs for uniform temperature distribution, each heater power input is the design variable. The objective function has been set as (14). The temperature of the sheet was set as $\left(T_{i}+T_{f}\right) / 2$. In steady state, only the calculation of radiation heat transfer and convective heat transfer is needed. The constraints were set in such a way that each heater input must be smaller than the maximum usable power $(650 \mathrm{~W})$. SQP (sequential quadratic programming) was used as the optimization algorithm [22-24]. Consider

$$
f=\frac{\left[\sum_{j=n+1}^{N}\left(q_{\mathrm{req}, j}^{\prime \prime}-q_{\mathrm{in}, j}^{\prime \prime}\right)^{2} \mathrm{RIGHT}\right]^{1 / 2}}{N} .
$$

In this section, the optimization was only carried out for the heater at the upper side. The optimal results of every heater power input are shown in Table 1; the value of each position expresses the percentage to maximum usable power.

For unsteady simulation in Section 4, another heater power distribution of the lower side was obtained using the same method.

\section{Optimal Heater Power Distribution Using Technology of Fault Tolerance}

When some heaters are damaged in the preheating process, some regions of the sheet will be not suitable for forming. The ideal method is to change the damaged heaters, but it will affect the mass production. In this case, the usable method is to find the new optimal heater power distribution under the condition of having the damaged heaters based on the technology of fault tolerance.

4.1. Effect of a Damaged Heater. In order to check the effect of a damaged heater, unsteady simulation should be carried out based on the heater power distributions of the upper and lower sides, and the effect of a damaged heater can be found from the temperature distribution of the sheet. When the upper side's heater element $(4,4)$ was assumed as the damaged 
TABLE 2: Relative temperature error caused by the damaged heater.

\begin{tabular}{ccccccccc}
\hline$\%$ & 1 & 2 & 3 & 4 & 5 & 6 & 7 & 8 \\
\hline 1 & -0.09 & -0.26 & -0.76 & -1.28 & -0.76 & -0.26 & -0.09 & -0.03 \\
2 & -0.11 & -0.36 & -1.39 & -2.84 & -1.38 & -0.36 & -0.11 & -0.04 \\
3 & -0.13 & -0.46 & -2.37 & -6.01 & -2.37 & -0.45 & -0.13 & -0.05 \\
4 & -0.13 & -0.49 & -2.91 & -8.12 & -2.91 & -0.49 & -0.14 & -0.05 \\
5 & -0.13 & -0.46 & -2.36 & -5.96 & -2.36 & -0.46 & -0.14 & -0.05 \\
6 & -0.12 & -0.38 & -1.42 & -2.88 & -1.42 & -0.38 & -0.12 & -0.05 \\
7 & -0.10 & -0.29 & -0.80 & -1.32 & -0.80 & -0.29 & -0.11 & -0.04 \\
8 & -0.08 & -0.21 & -0.47 & -0.67 & -0.47 & -0.21 & -0.09 & -0.04 \\
9 & -0.06 & -0.14 & -0.28 & -0.36 & -0.28 & -0.14 & -0.06 & -0.03 \\
10 & -0.05 & -0.10 & -0.17 & -0.21 & -0.17 & -0.10 & -0.05 & -0.02 \\
\hline
\end{tabular}

TABLE 3: Optimal heater power distribution with the damaged heater.

\begin{tabular}{ccccccccc}
\hline$\%$ & 1 & 2 & 3 & 4 & 5 & 6 & 7 & 8 \\
\hline 1 & 100.0 & 80.7 & 88.5 & $\mathbf{8 2 . 8}$ & 86.3 & 88.6 & 80.7 & 100.0 \\
2 & 49.8 & 0.0 & $\mathbf{1 . 9}$ & $\mathbf{0 . 0}$ & $\mathbf{1 . 9}$ & 0.0 & 0.0 & 49.8 \\
3 & 8.7 & 11.5 & $\mathbf{2 1 . 5}$ & $\mathbf{3 9 . 0}$ & $\mathbf{1 6 . 6}$ & 27.8 & 11.6 & 8.6 \\
4 & 70.8 & 34.5 & $\mathbf{3 9 . 4}$ & $\mathbf{X}$ & $\mathbf{4 0 . 4}$ & 30.1 & 34.3 & 70.9 \\
5 & 30.7 & 12.7 & $\mathbf{1 4 . 8}$ & $\mathbf{4 9 . 7}$ & $\mathbf{1 2 . 1}$ & 21.9 & 13.0 & 30.5 \\
6 & 30.5 & 13.0 & $\mathbf{2 4 . 6}$ & $\mathbf{2 . 1}$ & $\mathbf{2 1 . 8}$ & 22.4 & 12.7 & 30.6 \\
7 & 70.9 & 34.3 & 30.1 & $\mathbf{3 5 . 5}$ & 31.2 & 29.8 & 34.5 & 70.8 \\
8 & 8.6 & 11.6 & 27.8 & 23.0 & 22.9 & 28.0 & 11.5 & 8.6 \\
9 & 49.8 & 0.0 & 0.0 & 0.0 & 0.0 & 0.0 & 0.0 & 49.8 \\
10 & 100.0 & 80.6 & 88.6 & 86.3 & 86.4 & 88.5 & 80.7 & 100.0 \\
\hline
\end{tabular}

heater, the region affected by the damaged heater can be found in Table 2 .

The values in Table 2 show the relative temperature errors of each position compared with the temperature distribution of the normal case. The region expressed by italic numbers is the region significantly affected by the damaged heater.

4.2. Optimal Design with Technology of Fault Tolerance. In order to minimize the effect caused by the damaged heater, an optimization with the technology of fault tolerance was carried out $[25,26]$. In this case, the number of the design variables was 16 as shown in Table 2 with italic numbers. The objective function has been set as (5), where $q_{1, j}^{\prime \prime}$ is the heat flux with no damaged heater and $q_{2, j}^{\prime \prime}$ is the heat flux with damaged heater. The constraints were set in such a way that each design variable must be smaller than the maximum usable power $(650 \mathrm{~W})$. SQP was used as the optimization algorithm. Consider

$$
f=\frac{\left[\sum_{j=n+1}^{N}\left(q_{1, j}^{\prime \prime}-q_{2, j}^{\prime \prime}\right)^{2}\right]^{1 / 2}}{N} .
$$

Table 3 shows the optimal heater power distribution of upper surface under the condition of having the damaged heater based on the technology of fault tolerance. Table 4 shows the temperature difference of upper surface between the cases in which the upper surface's heater element $(4,4)$
TABLE 4: Temperature difference (normal versus damaged).

\begin{tabular}{ccccccccc}
\hline$\%$ & 1 & 2 & 3 & 4 & 5 & 6 & 7 & 8 \\
\hline 1 & 0.6 & 0.2 & 0.1 & -0.2 & 0.1 & 0.2 & 0.2 & 0.6 \\
2 & -0.2 & 0.0 & 0.1 & 0.6 & 0.0 & 0.0 & 0.0 & -0.2 \\
3 & 0.4 & 0.2 & 0.0 & 0.2 & 0.0 & 0.1 & 0.2 & 0.4 \\
4 & 0.0 & 0.1 & 0.2 & $-\mathbf{0 . 9}$ & 0.2 & 0.1 & 0.0 & 0.0 \\
5 & 0.2 & 0.0 & 0.0 & 0.7 & 0.0 & 0.0 & 0.1 & 0.2 \\
6 & 0.2 & 0.1 & -0.1 & -0.1 & -0.1 & 0.0 & 0.1 & 0.2 \\
7 & 0.0 & 0.0 & 0.1 & -0.3 & 0.1 & 0.1 & 0.0 & 0.0 \\
8 & 0.4 & 0.2 & 0.2 & 0.3 & 0.2 & 0.1 & 0.2 & 0.4 \\
9 & -0.2 & 0.0 & 0.1 & 0.2 & 0.1 & 0.1 & 0.0 & -0.2 \\
10 & 0.6 & 0.2 & 0.2 & 0.2 & 0.2 & 0.2 & 0.2 & 0.6 \\
\hline
\end{tabular}

was normal or not. Table 4 shows that the effect of the damaged heater has been neglected.

On the view of computational effort, 16 design variables were selected. When more design variables were selected, the error can be decreased more. In this study, acceptable results were obtained using a few design variables.

\section{Conclusion}

The analysis code which can be used to simulate the preheating process has been developed. In order to get the uniform distribution of temperature, the optimal distribution of heater power inputs has been found out at first under the condition of setting the temperature of sheet as the mean value of initial and objective temperature. In the following step, optimal heater power distribution with a damaged heater was found out using the technology of fault tolerance. The optimization strategy with technology of fault tolerance will be widely used in many kinds of engineering fields.

\section{Nomenclature}

$A_{s}: \quad$ Area of the ABS (Acrylonitrile-Butadiene-Styrene) sheet

$C_{P}$ : Specific heat of the ABS sheet

$F_{k-j}$ : View factor from the $k$ th element to the $j$ th element

$g$ : Acceleration of gravity

$h$ : Convective heat transfer coefficient

$J: \quad$ Radiosity

$k$ : Thermal conductivity of the ABS sheet

L: $\quad$ Characteristic length

$m: \quad$ Mass

$N$ : Total number of heater and sheet elements

$n_{h}$ : Number of heaters

$P$ : $\quad$ Circumference

$q_{\text {elec }}$ : Power to the heater

$q_{h}$ : Heat flow rate of the heater

$q_{\text {conv }}^{\prime}$ : Convective heat flux

$q_{\text {in }}^{\prime}:$ Heat flux input

$q_{\text {rad }}^{\prime}:$ Radiation heat flux 
$q_{\text {req }}^{\prime}$ : Required heat flux

$q_{1, j}^{\prime \prime}$ : Heat flux with no damaged heater

$q_{2, j}^{\prime \prime}$ : Heat flux with damaged heater

$\mathrm{Ra}_{L}$ : Rayleigh number

$T_{i}$ : Initial temperature

$T_{f}$ : Final temperature

$T_{\infty}$ : Environmental temperature

$t_{h}$ : Heating time

$v$ : Dynamic viscosity of air

$z$ : Position coordinate

$\beta$ : $\quad$ Volume expansion coefficient of air

$\rho: \quad$ Density of the ABS sheet

$\sigma: \quad$ Stefan-Boltzmann constant

$\varepsilon$ : Emissivity.

\section{Conflict of Interests}

The authors declare that there is no conflict of interests regarding the publication of this paper.

\section{Acknowledgment}

This material is based upon the works funded by the National Natural Science Foundation of China under Grant no. 61203042 .

\section{References}

[1] Z. Z. Li, Y. D. Shen, T. H. Cheng et al., Thermal Management Technology for Thermoforming Processes, Sichuan University Press, Sichuan, China, 2013.

[2] J. L. Throne, Technology of Thermoforming, Hanser Publishers, Munich, Germany, 1987.

[3] R. W. Jeffery, "Infrared heaters for thermoforming," Modern Plastics, vol. 42, no. 12, pp. 103-106, 168-171, 1965.

[4] F. M. Duarte and J. A. Covas, "IR sheet heating in roll fed thermoforming. Part 1. Solving direct and inverse heating problems," Plastics, Rubber and Composites, vol. 31, no. 7, pp. 307-317, 2002.

[5] F. M. Duarte and J. A. Covas, "Infrared sheet heating in roll fed thermoforming part 2-factors influencing inverse heating solution," Plastics, Rubber and Composites, vol. 32, no. 1, pp. 3239, 2003.

[6] F. M. Schmidt, Y. Le Maoult, and S. Monteix, "Modelling of infrared heating of thermoplastic sheet used in thermoforming process," Journal of Materials Processing Technology, vol. 143144, no. 1, pp. 225-231, 2003.

[7] J. G. Quintiere, J. L. Throne, and R. C. Progelhof, "Cyclical radiant heating of semitransparent sheets, clues to thermoforming," Technical Papers-Society of Plastics Engineers, vol. 18, part 2, pp. 820-823, 1972.

[8] T. Tsai James, "A study of radiation energy absorption in the thermoforming of plastics foam sheets," in Plast. Packag./ Acrylonitrile, Natl. Tech Conf., Soc. Plast. Eng., pp. 137-144, 1978.

[9] B. M. Pikkula, J. W. Tunnell, D. W. Chang, and B. Anvari, "Effects of droplet velocity, diameter, and film height on heat removal during cryogen spray cooling," Annals of Biomedical Engineering, vol. 32, no. 8, pp. 1131-1140, 2004.
[10] Y.-Z. Chang, T.-T. Wen, and S.-J. Liu, "Derivation of optimal processing parameters of polypropylene foam thermoforming by an artificial neural network," Polymer Engineering and Science, vol. 45, no. 3, pp. 375-384, 2005.

[11] C. Yang and S.-W. Hung, "Modeling and optimization of a plastic thermoforming process," Journal of Reinforced Plastics and Composites, vol. 23, no. 1, pp. 109-121, 2004.

[12] R. DiRaddo, D. Laroche, A. Bendada, and T. Ots, "Optimization of thermoforming with process modeling," in Proceedings of the 57th Annual Technical Conference, vol. 1, pp. 844-849, Society of Plastics Engineers, 1999.

[13] C.-H. Wang and H. F. Nied, "Temperature optimization for improved thickness control in thermoforming," Journal of Materials Processing and Manufacturing Science, vol. 8, no. 2, pp. 113-126, 2000.

[14] J. L. Throne and M. Kmetz, "Computer-aided design in thermoforming," Plastics Engineering, vol. 45, no. 9, pp. 35-38, 1989.

[15] R. Siegel and J. R. Howell, Thermal Radiation Heat Transfer, chapter 6-8, McGraw-Hill, New York, NY, USA, 2nd edition, 1997.

[16] A. Bejan, Convection Heat Transfer, chapter 4, John Wiley \& Sons, New York, NY, USA, 2nd edition, 1995.

[17] M. N. Ozisik, Heat Conduction, John Wiley \& Sons, New York, NY, USA, 2nd edition, 1993.

[18] Y. S. Lee, T. J. Kang, and J. K. Lee, "A study on heat transfer through plain woven fabric. An approach through finite difference method," Journal of the Korean Fiber Society, vol. 28, no. 9, pp. 707-714, 1991.

[19] J. E. Oh, C. H. Lee, H. J. Sim, H. J. Lee, S. H. Kim, and J. Y. Lee, "Development of a system for diagnosing faults in rotating machinery using vibration signals," International Journal of Precision Engineering and Manufacturing, vol. 8, no. 3, pp. 5459, 2007.

[20] M. Sahin and H. J. Wilson, "A semi-staggered dilation-free finite volume method for the numerical solution of viscoelastic fluid flows on all-hexahedral elements," Journal of Non-Newtonian Fluid Mechanics, vol. 147, no. 1-2, pp. 79-91, 2007.

[21] Z. Z. Li, K. S. Heo, and S. Y. Seol, “Time-dependent optimal heater control in ther moforming preheating using dual optimization steps," International Journal of Precision Engineering and Manufacturing, vol. 9, no. 4, pp. 51-56, 2008.

[22] Z. Z. Li, Y. D. Shen, K. S. Heo et al., "Feasible optimal design of high temperature vacuum furnace using experiences and thermal analysis database," Journal of Thermal Science and Technology, vol. 2, no. 1, pp. 123-133, 2007.

[23] Z. Z. Li, M. Y. Park, J. W. Lee, Y. H. Byun, and C. J. Lee, "Optimal design of high temperature vacuum furnace using thermal analysis database," Transaction of the KSME B, vol. 30, no. 6, pp. 594-601, 2006.

[24] Z.-Z. Li, T.-H. Cheng, D.-J. Xuan, M. Ren, G.-Y. Shen, and Y.D. Shen, "Optimal design for cooling system of batteries using DOE and RSM," International Journal of Precision Engineering and Manufacturing, vol. 13, no. 9, pp. 1641-1645, 2012.

[25] R.-T. Yang, H.-T. Liao, Y.-K. Yang, and S.-S. Lin, "Modeling and optimization in precise boring processes for aluminum alloy 6061T6 components," International Journal of Precision Engineering and Manufacturing, vol. 13, no. 1, pp. 11-16, 2012.

[26] M. M. Seron and J. A. de Doná, "Actuator fault tolerant multi-controller scheme using set separation based diagnosis," International Journal of Control, vol. 83, no. 11, pp. 2328-2339, 2010. 

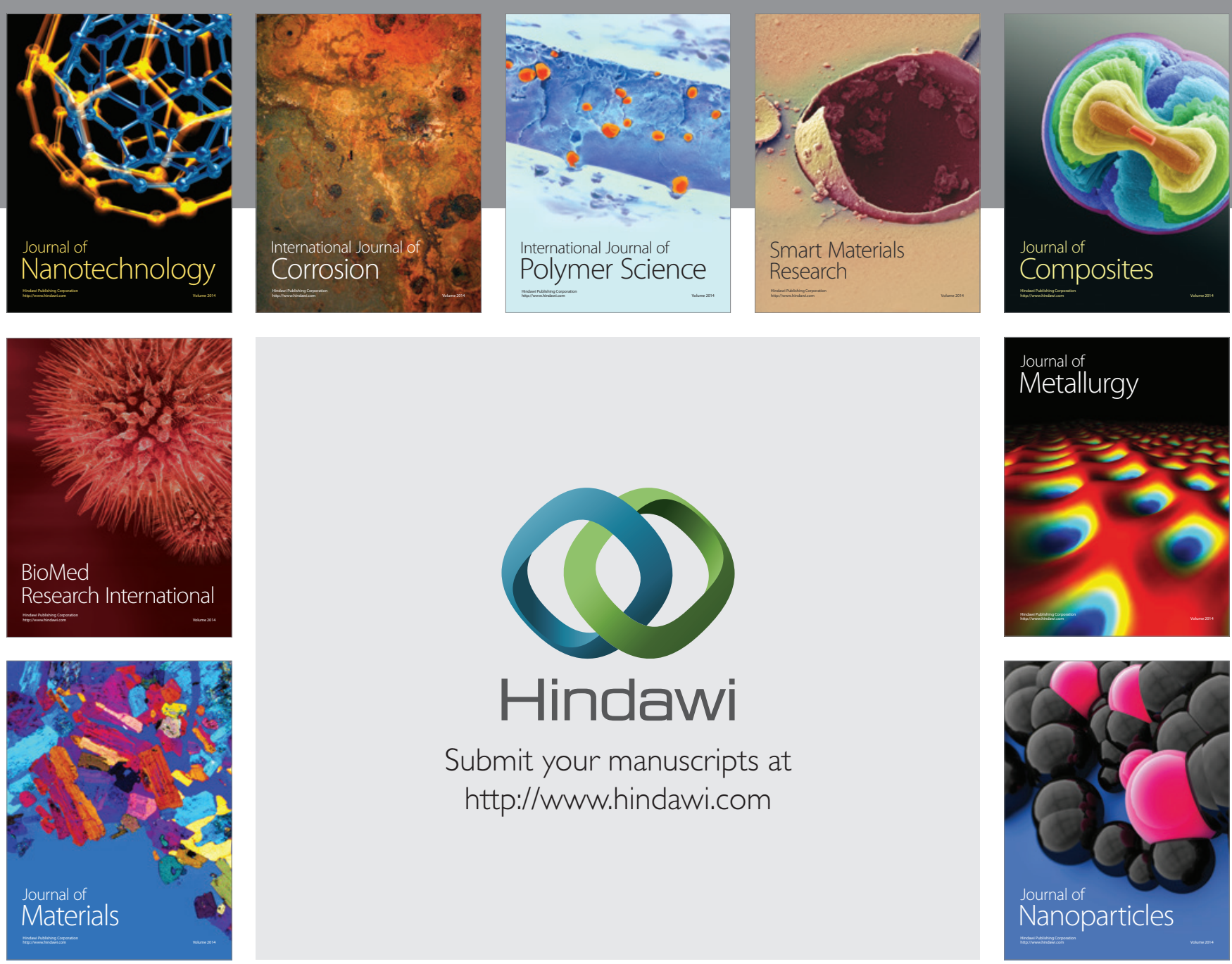

Submit your manuscripts at http://www.hindawi.com
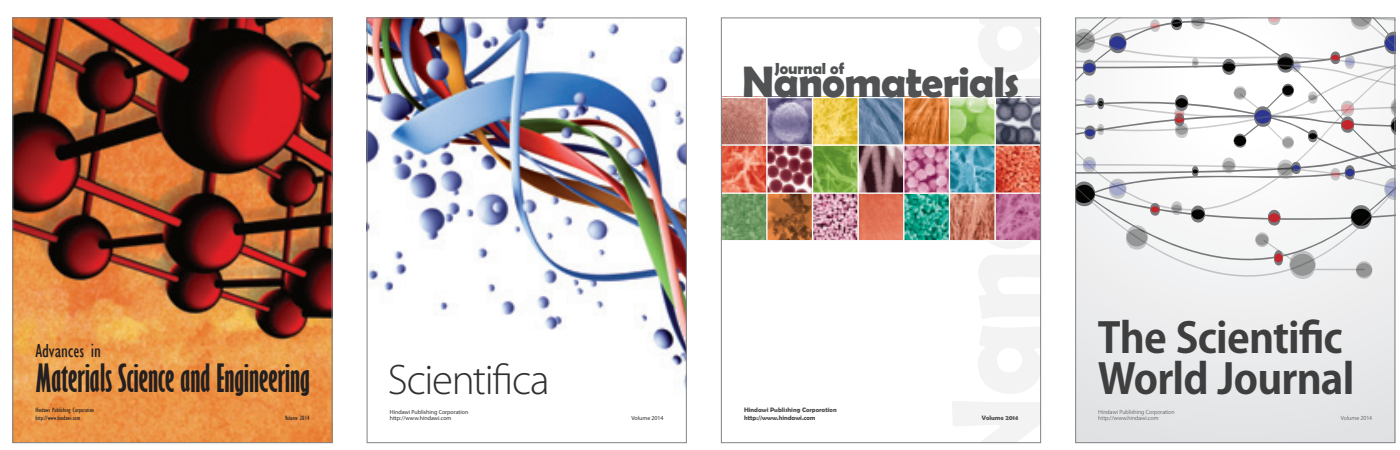

\section{The Scientific World Journal}
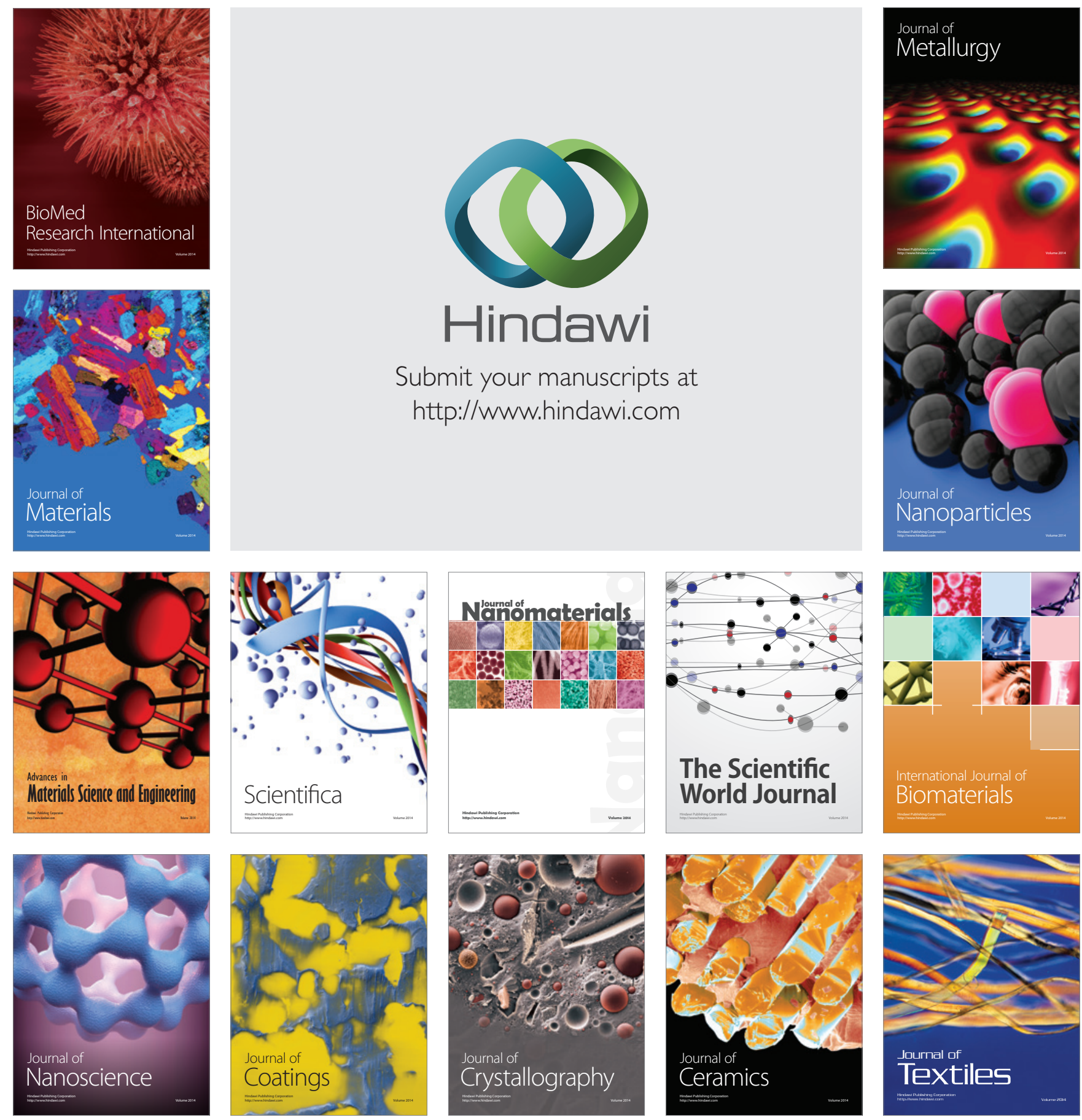